\title{
Free vibration analysis of homogeneous and FGM skew plates resting on variable Winkler-Pasternak elastic foundation
}

\author{
Mohamad Javad Ketabdari, Alireza Allahverdi, Sayad Boreyri ${ }^{\mathrm{a}}$ and Manouchehr \\ FADAVIE ARDESTANi
}

Department of Marine Technology, Amirkabir University of Technology, Tehran, Iran

Received 25 February 2015, Accepted 24 June 2015

\begin{abstract}
In this research study, free vibration of homogeneous and functionally graded skew plates resting on Winkler-Pasternak elastic foundation is investigated. The elastic foundation is assumed to be a combination of Winkler and Pasternak elastic support with linearly or parabolically variable stiffness coefficients along the directions. Plate skewness is obtained by using a transformation from Cartesian coordinate to oblique coordinate system. The energy of the functionally graded skew plate and the elastic foundation is derived, and the natural frequency of the plate is calculated by the Rayleigh-Ritz method. The results are compared with available results in the literature, showing an excellent agreement. Furthermore, a parametric study is carried out to thoroughly investigate the effects of different boundary conditions, skew angles, inhomogeneity factors, and variable elastic foundation stiffness on the free vibration of skew plates.
\end{abstract}

Key words: Free vibration / skew plate / FGM plate / Winkler-Pasternak elastic foundation / RayleighRitz method

\section{Introduction}

Composite materials are manufactured based on different industrial needs to optimize the response to external loads and reduce the residual and thermal stresses at desired regions of structures. Functionally graded materials (FGMs) were first introduced by the Japanese researchers in 1984 [1]. They are relatively new composites with spatially continuous variation of mechanical properties along one or more directions. This is achieved by gradually changing the composition of the constituent materials, usually ceramics and metals, so that dealing with interfacial stress concentrations can be avoided.

Skew plates are one of the important elements in civil, aerospace and marine industries. In spite of the mathematical difficulties involved in their study, they have found a wide range of application in modern structures such as parallelogram slabs in buildings and bridges, swept wings of aircrafts and ship hulls. Therefore, many studies have been focused on these types of plates. One of the earliest researches was carried out by Kaul and Cadambe [2] to find the fundamental frequencies of skew plates using an energy-based method. Since then a number of other researches tried to find better solutions for such structures. In 2000, Wang et al. [3] used Ritz method

${ }^{a}$ Corresponding author: sayyad.boreyri@aut.ac.ir to find vibration frequencies of skew laminated sandwich plates. In 2003, Woo et al. [4] studied the free vibration of such plates. In 2009, Zhao [5], used kp-Ritz method for studying free vibration of rectangular and skew FG plates.

Elastic foundations may shift the natural frequencies of structures. Free vibration of thin rectangular plates resting on Winkler-Pasternak elastic foundation was studied by Civalek using differential quadrature method in 2007 [6]. Akhavan et al. [7] found the exact solution for rectangular Mindlin plates resting on Winkler-Pasternak foundation in 2009. Atmane et al. [8] used a new shear deformation theory for FGM rectangular plates resting on elastic Winkler-Pasternak foundation, in 2010. More recently in 2013, Joodaky et al. [9], used an extended Kantorovich method to study the deflection of a thin skew plate resting on Winkler elastic foundation. Since then, a number of researches have been performed to thoroughly investigate the vibration characteristics of such structures. According to this literature survey and best knowledge of the authors, not a single research has been carried out on free vibration of skew homogeneous or FGM plates on Winkler-Pasternak foundation, specifically with variable foundation characteristics which are more practical in industry. The main purpose of this study is to thoroughly investigate free vibration of such structures. 


\section{Nomenclature}

\begin{tabular}{|ll|}
\hline$B_{k}, C_{k}, \varphi_{k}, \psi_{k}$ & Polynomial orthogonal functions \\
$D, E$ & Flexural rigidity and modulus of elasticity of the plate, respectively \\
$\bar{k}_{\mathrm{w}}, \bar{k}_{\mathrm{p}}$ & Winkler and Pasternak non-dimensional coefficients, respectively \\
$P_{\mathrm{c}}, P_{\mathrm{m}}$ & Any mechanical properties of the ceramic or metal plate \\
$T_{\mathrm{pl}}^{*}$ & Kinetic energy of the plate \\
$U_{\mathrm{pl}}, U_{\mathrm{W}}, U_{\mathrm{P}}$ & Potential energy of the plate, Winkler and Pasternak foundation, respectively \\
$\varepsilon \eta$ & Transformed axes of $x, y$ in oblique coordinate system \\
$\theta$ & Skew angle \\
$\omega, \beta$ & Frequency and normalized frequency of the plate \\
$\bar{\rho}$ & Density of the plate \\
$z_{\mathrm{np}}, z_{\mathrm{mp}}$ & Neutral and mid plane location, respectively \\
$\Delta_{z}$ & Distance between $z_{\mathrm{np}}$ and $z_{\mathrm{mp}}$ \\
\hline
\end{tabular}

Therefore, study of skew homogeneous and FGM plates resting on variable elastic foundation is investigated in this paper. In section two, the theory and method of solution are introduced. This section mainly deals with the derivation of formulation to calculate the energy of FGM skew plates resting on Winkler-Pasternak foundations. Thereafter, the results are validated and fully discussed in section three, and finally a conclusion on the analysis of the vibration of such structures is drawn by the authors in Section 4.

\section{Theory and methodology}

\subsection{FGM materials}

The FGM plate used in this research is a plate made of ceramic and metal. Material properties of the plate vary through the thickness from pure metal to pure ceramic smoothly and continuously. Change in material properties can be modeled based on the power law distribution, the exponential distribution [10], the Mori-Tanaka scheme $[11,12]$ and functionally graded materials with porosities [13]. In this study, the power law distribution is employed as in the form of:

$$
P(z)=\left(P_{\mathrm{c}}-P_{\mathrm{m}}\right)\left(\frac{2 z+h}{2 h}\right)^{n}+P_{\mathrm{m}} ; \frac{-h}{2}<z<\frac{h}{2}
$$

where $h$ is the thickness, and indexes $\mathrm{c}$ and $\mathrm{m}$ refer to ceramic and metal, respectively. $P(z)$ is the inhomogeneity function and can be either $E(z)$, elasticity modulus or $\rho(z)$, density of the plate. It can be seen that elasticity modulus and density are not constant, as they are functions of plate thickness. It is also seen that for $n=0$, pure ceramic, and for $n=\infty$, pure metal is obtained.

It should be mentioned that the neutral plane location, $z_{\mathrm{np}}$ is different from the mid plane location, $z_{\mathrm{mp}}$ for FG plates $[10,14]$. It is located at $z_{\mathrm{np}}=z_{\mathrm{mp}}+\Delta_{z}$. Here, $\Delta_{z}$, the distance of neutral plane from the middle plane, can be calculated using Equation (2) wherein, $z$ must be measured from the mid plane [15]

$$
\Delta_{z}=\frac{\int_{-h / 2}^{+h / 2} z P(z) \mathrm{d} z}{\int_{-h / 2}^{+h / 2} P(z) \mathrm{d} z}
$$

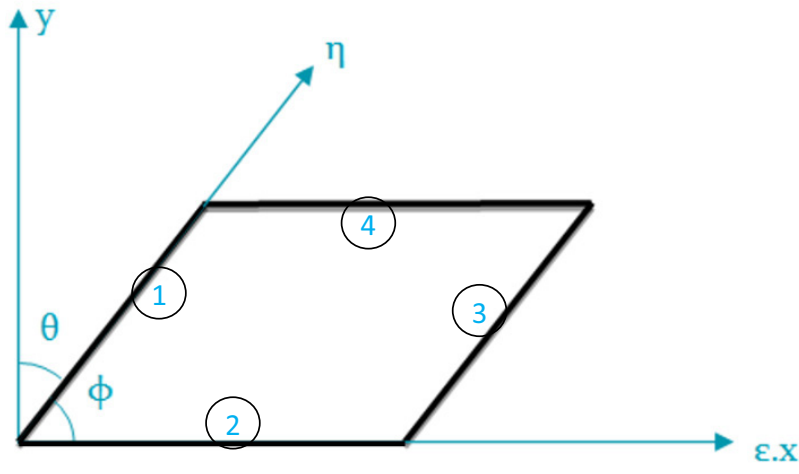

Fig. 1. Oblique and Cartesian coordinate systems.

\subsection{Coordinate system}

In order to analyze the structure, Cartesian coordinate system must be transformed into oblique coordinate system of Figure 1 using Equation (3) $[9,16]$. It should be noted that numbers in the circles in Figure 1 refer to the sequence of boundary conditions in this study. A skew SCCC plate means the one with a simple support condition at edge 1 , and clamped condition at the remaining edges, or a skew CCSS plate has clamped condition at edges 1 and 2, and simple support condition at edges 3 and 4.

$$
\left\{\begin{array}{l}
\varepsilon=x-y \tan \theta \\
\eta=\frac{y}{\cos \theta}
\end{array}\right.
$$

Consequently, the operator $\nabla^{2}$ in Cartesian coordinate system is rewritten in the suitable form for oblique coordinate system as Equation (4)

$$
\bar{\nabla}^{2}=\frac{1}{\cos \theta}\left(\frac{\partial^{2}}{\partial \varepsilon^{2}}-2 \sin \theta \frac{\partial^{2}}{\partial \varepsilon \partial \eta}+\frac{\partial^{2}}{\partial \eta^{2}}\right)
$$

\subsection{Energy of the skew plate}

Potential and kinetic energy of the system can be calculated using Rayleigh-Ritz method in order to derive 
vibration frequencies. The potential energy, $U_{0}$, and kinetic energy, $T_{0}$, of a rectangular plate can be found using Equation (5):

$$
\begin{aligned}
U_{0}= & \frac{1}{2} \iiint\left(\frac{E z^{2}}{1-v^{2}}\right)\left\{\left(\frac{\partial^{2} W}{\partial x^{2}}+\frac{\partial^{2} W}{\partial y^{2}}\right)^{2}\right. \\
& \left.+2(1-\nu)\left[\left(\frac{\partial^{2} W}{\partial x \partial y}\right)^{2}-\frac{\partial^{2} W}{\partial x^{2}} \frac{\partial^{2} W}{\partial y^{2}}\right]\right\} \mathrm{d} x \mathrm{~d} y \mathrm{~d} z,
\end{aligned}
$$

$$
T_{0}=\frac{1}{2} \iiint \rho\left(\frac{\partial W}{\partial t}\right)^{2} \mathrm{~d} x \mathrm{~d} y \mathrm{~d} z
$$

Introducing Equations (3) and (4) into Equation (5), the maximum potential and kinetic energy of a skew FGM plate can be achieved as:

$$
\begin{aligned}
U_{\mathrm{pl}}= & \frac{1}{2} \frac{a b}{a^{4} \cos ^{3}(\theta)} \int_{-h / 2}^{+h / 2} \frac{E(z) z^{2}}{\left(1-v^{2}\right)} \mathrm{d} z \int_{0}^{1} \int_{0}^{1}\left\{\left(\frac{\partial^{2} W}{\partial \varepsilon^{2}}\right)^{2}\right. \\
& +\left(\frac{a}{b}\right)^{4}\left(\frac{\partial^{2} W}{\partial \eta^{2}}\right)^{2}+4\left(\frac{a}{b}\right)^{2} \sin ^{2} \theta\left(\frac{\partial^{2} W}{\partial \varepsilon \partial \eta}\right)^{2} \\
& +2\left(\frac{a}{b}\right)^{2} \frac{\partial^{2} W}{\partial \varepsilon^{2}} \frac{\partial^{2} W}{\partial \eta^{2}} \\
& -4\left(\frac{a}{b}\right) \sin (\theta) \frac{\partial^{2} W}{\partial \varepsilon \partial \eta}\left[\frac{\partial^{2} W}{\partial \varepsilon^{2}}+\left(\frac{a}{b}\right)^{2} \frac{\partial^{2} W}{\partial \eta^{2}}\right] \\
& -2(1-\nu)\left(\frac{a}{b}\right)^{2} \cos ^{2}(\theta)\left(\frac{\partial^{2} W}{\partial \varepsilon^{2}} \frac{\partial^{2} W}{\partial \eta^{2}}\right. \\
& \left.\left.-\left(\frac{\partial^{2} W}{\partial \varepsilon \partial \eta}\right)^{2}\right)\right\}^{2} \mathrm{~d} \varepsilon \mathrm{d} \eta, \\
T_{\mathrm{pl}}= & \frac{1}{2} a b \cos \theta \int_{-\frac{h}{2}}^{+\frac{h}{2}} \rho(z) \mathrm{d} z \iint\left(\frac{\partial W}{\partial t}\right)^{2} \mathrm{~d} \varepsilon \mathrm{d} \eta
\end{aligned}
$$

\subsection{Energy of the elastic foundation}

The energy of the elastic foundation includes two parts: the energy due to Winkler-type foundation, Equation (8), and Pasternak-type foundation, Equation (9)

$$
\begin{aligned}
U_{\mathrm{W}}= & \frac{1}{2} a b D \cos \theta \iint \bar{k}_{\mathrm{w}} w^{2} \mathrm{~d} \varepsilon \mathrm{d} \eta \\
U_{\mathrm{P}}= & \frac{a b D}{2 \cos (\theta)} \iint \bar{k}_{\mathrm{p}}\left[\left(1+\left(\frac{\mathrm{a}^{2}}{\mathrm{~b}^{2}}-1\right) \sin ^{2}(\theta)\right)\left(\frac{\partial w}{\partial \varepsilon}\right)^{2}\right. \\
& \left.+\frac{\mathrm{a}^{2}}{\mathrm{~b}^{2}}\left(\frac{\partial w}{\partial \eta}\right)^{2}-2 \frac{\mathrm{a}^{2}}{\mathrm{~b}^{2}} \sin \theta\left(\frac{\partial w}{\partial \varepsilon} \frac{\partial w}{\partial \eta}\right)\right] \mathrm{d} \varepsilon \mathrm{d} \eta \\
\bar{k}_{\mathrm{w}}= & \frac{k_{w} a^{2} b^{2}}{D}, \quad \bar{k}_{\mathrm{p}}=\frac{k_{p} a b}{D}
\end{aligned}
$$

where $U_{\mathrm{W}}, U_{\mathrm{P}}$ are potential energy due to Winkler and Pasternak foundations, and $\bar{k}_{\mathrm{w}}, \bar{k}_{\mathrm{p}}$ are Winkler and Pasternak non-dimensional coefficients, respectively. The

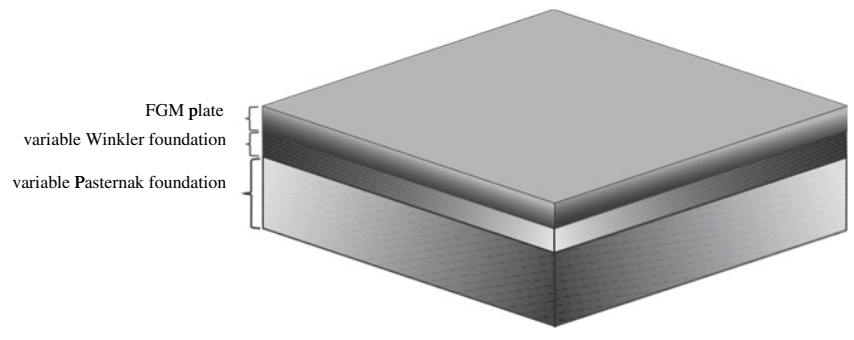

Fig. 2. An FGM skew plate on Winkler-Pasternak type foundation.

total structure is depicted in Figure 2. It should be noted that $\bar{k}_{\mathrm{w}}=\bar{k}_{\mathrm{w}}(\varepsilon, \eta)$, and $\bar{k}_{\mathrm{p}}=\bar{k}_{\mathrm{p}}(\varepsilon, \eta)$, which means that the foundation stiffness is variable along the directions. The potential, $U$, and kinetic energy of the system can be calculated using Equations (10) and (7) respectively.

$$
U=U_{\mathrm{pl}}+U_{\mathrm{W}}+U_{\mathrm{P}}
$$

\subsection{Rayleigh-Ritz formulation}

For a harmonic oscillation, the kinetic energy of Equation (7) can be simplified as Equation (11). Therefore, natural frequencies can be found from Equation (12) under the condition that $w=w(\varepsilon, \eta)$ is defined.

$$
\begin{aligned}
T_{\mathrm{pl}}^{*} & =\omega^{2} \\
\omega^{2} & =\frac{U}{T^{*}}
\end{aligned}
$$

To define $w(\varepsilon, \eta)$, a set of polynomial functions has been used in this study. These functions along $\varepsilon$-direction are in the form of Equation (13). Similar functions can be selected along $\eta$-direction, and therefore, two-dimensional orthogonal functions can be produced.

$$
\begin{aligned}
\varphi_{1}(\varepsilon) & =\left(\varepsilon-B_{1}\right) \varphi_{0}(\varepsilon) \\
\varphi_{k}(\varepsilon) & =\left(\varepsilon-B_{k}\right) \varphi_{k-1}(\varepsilon)-C_{k} \varphi_{k-2}(\varepsilon) \\
B_{k} & =\int_{a}^{b} \varepsilon \psi(\varepsilon) \varphi_{k-1}^{2}(\varepsilon) \mathrm{d} x / \int_{a}^{b} \psi(\varepsilon) \varphi_{k-1}^{2}(\varepsilon) \mathrm{d} \varepsilon \\
C_{k} & =\int_{a}^{b} \varepsilon \psi(\varepsilon) \varphi_{k-1}(\varepsilon) \varphi_{k-2}(\varepsilon) \mathrm{d} \varepsilon / \int_{a}^{b} \psi(\varepsilon) \varphi_{k-2}^{2}(\varepsilon) \mathrm{d} \varepsilon
\end{aligned}
$$

Here, $\psi(\varepsilon)$ is the weight function and considered to be constant $1 . B_{k}$ and $C_{k}$ are some coefficients. Orthogonal functions, $\varphi_{k}(\varepsilon)$ should satisfy the following conditions:

$$
\int_{a}^{b} \varepsilon \psi(\varepsilon) \varphi_{k}(\varepsilon) \varphi_{l}(\varepsilon) \mathrm{d} \varepsilon=\left\{\begin{array}{l}
0 \quad \text { if } k \neq l \\
a_{k l} \text { if } k=l
\end{array}\right.
$$

The function $\varphi_{0}(\varepsilon)$ should be chosen according to the boundary conditions. Further information is available in references $[17,18]$. Substituting these equations into Equation (12) gives the natural frequencies of the skew FGM plate resting on Winkler-Pasternak foundation. 
M.J. Ketabdari et al.: Mechanics \& Industry 17, 107 (2016)

Table 1. 1st five frequency parameters of the homogeneous skew plate.

\begin{tabular}{|c|c|c|c|c|c|c|c|}
\hline \multirow{2}{*}{$\theta$} & \multirow{2}{*}{ method } & \multicolumn{5}{|c|}{ Mode } & \multirow[t]{2}{*}{$\%$ error of the 5 th mode } \\
\hline & & 1 & 2 & 3 & 4 & 5 & \\
\hline \multicolumn{7}{|c|}{$\mathrm{CCCC}$} & \multirow{3}{*}{0.14} \\
\hline \multirow{2}{*}{0} & Present & 35.9885 & 73.4129 & 73.4121 & 108.2574 & 131.7788 & \\
\hline & [19] & 35.9878 & 73.4048 & 73.4048 & 108.2679 & 131.5988 & \\
\hline \multirow{2}{*}{15} & Present & 38.200 & 72.914 & 82.645 & 109.563 & 139.355 & \multirow{2}{*}{0.28} \\
\hline & [20] & 38.187 & 72.896 & 82.618 & 109.56 & 138.97 & \\
\hline \multirow{2}{*}{30} & Present & 46.092 & 81.602 & 105.199 & 119.303 & 165.970 & \multirow{2}{*}{0.59} \\
\hline & {$[20]$} & 46.089 & 81.601 & 105.17 & 119.25 & 164.98 & \\
\hline \multirow{2}{*}{45} & Present & 65.688 & 106.505 & 148.613 & 157.762 & 199.491 & \multirow{2}{*}{1.3} \\
\hline & {$[20]$} & 65.643 & 106.49 & 148.31 & 157.23 & 196.77 & \\
\hline \multicolumn{8}{|c|}{ SSSS } \\
\hline 0 & Present & 19.73922 & 49.3772 & 49.3772 & 78.9992 & 98.90416 & \multirow{2}{*}{0.21} \\
\hline 0 & {$[20]$} & 19.73921 & 49.34802 & 49.3480 & 78.95684 & 98.69608 & \\
\hline \multirow{2}{*}{15} & Present & 20.880 & 48.206 & 56.142 & 79.097 & 104.355 & \multirow{2}{*}{0.34} \\
\hline & {$[20]$} & 20.868 & 48.205 & 56.107 & 79.043 & 104.00 & \\
\hline \multirow{2}{*}{30} & Present & 25.066 & 52.639 & 72.152 & 84.017 & 124.086 & \multirow{2}{*}{1.04} \\
\hline & {$[20]$} & 24.899 & 52.638 & 71.711 & 83.829 & 122.82 & \\
\hline \multirow{2}{*}{45} & Present & 35.269 & 66.295 & 101.120 & 109.815 & 143.197 & \multirow[b]{2}{*}{1.7} \\
\hline & {$[20]$} & 34.755 & 66.277 & 100.25 & 107.01 & 140.80 & \\
\hline
\end{tabular}

\section{Results and discussion}

\subsection{Model validation}

In order to validate the model, free vibration of the homogeneous skew plates has been investigated and the non-dimensional natural frequencies have been compared to available results in the literature considering no elastic foundation, that is $\bar{k}_{\mathrm{w}}=\bar{k}_{\mathrm{p}}=0$. This is illustrated in Table 1. For more general results non-dimensional frequencies, $\beta=\omega a^{2}\left(\frac{\bar{\rho} h}{D}\right)^{0.5}$ are presented in which $D$ and $\bar{\rho}$ are:

$$
D=\int_{-\frac{h}{2}}^{+\frac{h}{2}} \frac{E(z) z^{2}}{\left(1-v^{2}\right)} \mathrm{d} z \text { and } \bar{\rho}=\frac{1}{h} \int_{-\frac{h}{2}}^{+\frac{h}{2}} \rho(z) \mathrm{d} z
$$

From Table 1 it is seen that the results are compatible with those in the literature with great accuracy. A little deviation, however, is seen in higher mode frequencies. The highest value of error can be seen in the 5th mode when $\theta$ equals 45 , which is less that $2 \%$. This error of the fifth mode is quite acceptable. In fact, the accuracy of the results is proved to decrease for higher skew angles and higher mode shapes [21]. More results for first three normalized frequencies of homogeneous plates with other boundary conditions are presented in Table 2 .

Due to lack of valid data for vibration of skew plates on elastic foundation, the results of free vibration of the plate on Winkler-Pasternak foundation have been compared with rectangular results in the literature by setting $\theta=0$. This is presented in Table 3. It is seen that the present results are remarkably accurate for the fundamental natural frequency.

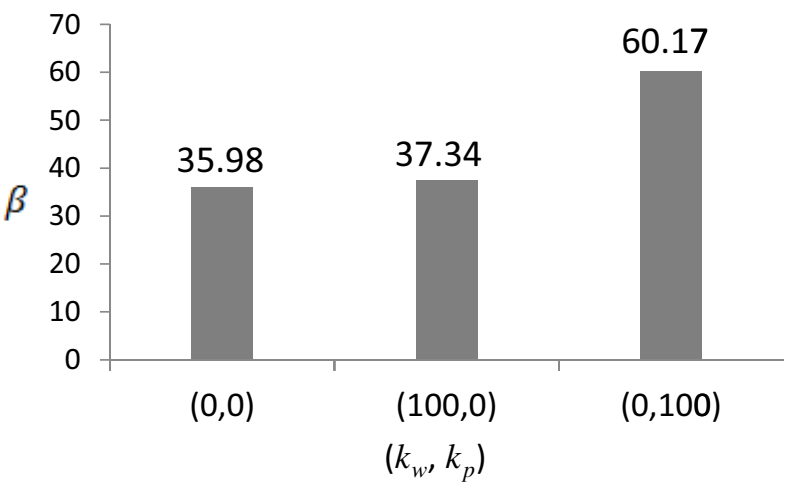

Fig. 3. Effects of Winkler and Pasternak coefficients on frequency parameter for clamped rectangular plate.

\subsection{Homogeneous skew plates on Winkler-Pasternak type foundation}

In this section, results for normalized natural frequency, $\beta$ of a homogeneous skew plate on elastic foundation are presented. In Table 4 , the first five frequencies of simply supported and clamped skew plates are shown on Winkler-Pasternak elastic foundations. A comparison between Tables 1 and 4 indicates that adding an elastic foundation increases the natural frequency of the plate - as seen in Table 3. More importantly, these frequency changes are more considerable with the changes in Pasternak foundation rather than Winkler foundation. This is clearly shown in Figure 3 when for $\bar{k}_{\mathrm{p}}=0$ the changes in frequency due to Winkler foundation are not substantial. However, when a Pasternak foundation is set, the changes are more noticeable in natural frequency. It should be mentioned that the selection of foundation coefficients is on the basis of references [23-27], wherein more data for the interaction of structural-foundation of rectangular plates have been presented. More results for the 
M.J. Ketabdari et al.: Mechanics \& Industry 17, 107 (2016)

Table 2. 1st three frequency parameters of the homogeneous skew plate.

\begin{tabular}{ccccccccccc}
\hline \multirow{2}{*}{$\theta$} & \multirow{2}{*}{ method } & \multicolumn{3}{c}{ CCSS } & \multicolumn{3}{c}{ CSSS } & \multicolumn{3}{c}{ SCCC } \\
\cline { 3 - 10 } & & 1 & 2 & 3 & 1 & 2 & 3 & 1 & 2 & 3 \\
\hline 0 & Present & 27.07 & 60.61 & 60.86 & 23.65 & 51.70 & 58.70 & 31.87 & 63.50 & 71.36 \\
& {$[22]$} & 27.05 & 60.55 & 60.55 & 23.64 & 51.81 & 58.65 & 31.82 & 63.34 & 71.08 \\
\multirow{2}{*}{15} & Present & 28.69 & 60.00 & 68.47 & 25.05 & 52.80 & 64.01 & 33.81 & 65.19 & 77.69 \\
& {$[20]$} & 28.72 & 59.74 & 68.73 & 25.02 & 52.76 & 63.91 & 33.74 & 64.96 & 77.35 \\
\multirow{2}{*}{30} & Present & 34.30 & 66.46 & 87.36 & 30.10 & 58.73 & 81.14 & 40.80 & 73.38 & 98.37 \\
& {$[20]$} & 34.54 & 66.18 & 87.67 & 29.94 & 58.64 & 80.68 & 40.61 & 73.04 & 97.55 \\
\multirow{2}{*}{45} & Present & 48.33 & 85.39 & 123.66 & 42.89 & 75.22 & 111.92 & 58.27 & 95.72 & 137.19 \\
& {$[20]$} & 48.83 & 85.03 & 122.97 & 41.96 & 74.95 & 111.29 & 57.50 & 94.99 & 135.35 \\
\hline
\end{tabular}

Table 3. Fundamental frequency of a simply supported homogeneous rectangular plate on elastic foundation.

\begin{tabular}{cccc}
\hline$\left(\bar{k}_{\mathrm{w}}, \bar{k}_{\mathrm{p}}\right)$ & Akhavan et al. [7] & Atmane et al. [8] & Present \\
\hline$(0,0)$ & 19.7391 & 19.7391 & 19.7392 \\
$(100,10)$ & 26.2112 & 26.2112 & 26.2112 \\
$(1000,100)$ & 57.9961 & 57.9962 & 57.9961 \\
\hline
\end{tabular}

Table 4. Frequency parameter of a homogeneous skew plate on Winkler-Pasternak foundation.

\begin{tabular}{cccccccccc}
\hline \multirow{2}{*}{$\left(\bar{k}_{\mathrm{w}}, \bar{k}_{\mathrm{p}}\right)$} & \multicolumn{9}{c}{ SSSS } \\
\cline { 2 - 8 } & $(0,100)$ & $(0,1000)$ & $(100,0)$ & $(100,100)$ & $(0,100)$ & $(0,1000)$ & $(100,0)$ & $(100,100)$ \\
\hline 0 & Mode & & & & & & & \\
\hline & 1 & 48.616 & 141.876 & 22.127 & 49.634 & 60.173 & 151.703 & 37.3491 & 60.9978 \\
& 2 & 85.848 & 227.559 & 50.351 & 86.429 & 104.946 & 243.129 & 74.090 & 105.445 \\
& 3 & 85.848 & 227.559 & 50.351 & 86.429 & 104.946 & 243.129 & 74.090 & 105.445 \\
& 4 & 118.869 & 291.875 & 79.587 & 119.289 & 143.421 & 311.735 & 108.718 & 143.843 \\
& 5 & 140.55 & 329.768 & 99.806 & 140.905 & 168.298 & 154.012 & 132.158 & 168.594 \\
\hline 15 & 1 & 49.515 & 143.506 & 23.086 & 50.485 & 61.969 & 237.825 & 39.431 & 62.746 \\
& 2 & 83.546 & 221.119 & 49.224 & 84.142 & 103.215 & 257.384 & 73.574 & 103.709 \\
& 3 & 92.582 & 239.519 & 57.074 & 93.160 & 113.997 & 308.906 & 83.227 & 114.450 \\
& 4 & 117.866 & 287.524 & 79.832 & 118.379 & 143.527 & 358.188 & 110.060 & 143.910 \\
& 5 & 145.078 & 334.568 & 105.670 & 145.813 & 174.780 & 327.299 & 139.701 & 175.118 \\
\hline 30 & 1 & 52.802 & 148.985 & 26.796 & 53.615 & 68.526 & 161.896 & 47.027 & 69.155 \\
& 2 & 85.645 & 219.928 & 53.499 & 86.149 & 109.293 & 239.205 & 82.153 & 109.688 \\
& 3 & 107.149 & 259.680 & 73.134 & 107.553 & 134.844 & 282.184 & 105.751 & 135.165 \\
& 4 & 120.184 & 282.719 & 85.146 & 120.544 & 150.004 & 306.598 & 119.835 & 150.293 \\
& 5 & 164.057 & 352.049 & 127.248 & 164.320 & 199.014 & 378.506 & 167.235 & 199.232 \\
\hline 45 & 1 & 61.365 & 160.914 & 37.105 & 61.938 & 85.411 & 179.918 & 66.273 & 85.824 \\
& 2 & 95.470 & 226.541 & 67.041 & 95.839 & 129.910 & 253.406 & 106.981 & 130.182 \\
& 3 & 134.408 & 287.348 & 104.634 & 134.671 & 174.987 & 318.265 & 150.563 & 175.189 \\
& 4 & 141.722 & 297.744 & 111.911 & 141.971 & 184.209 & 331.476 & 159.170 & 184.401 \\
& 5 & 191.749 & 363.398 & 161.726 & 191.934 & 232.994 & 388.393 & 208.713 & 233.145 \\
\hline
\end{tabular}

interaction of structure-foundation are available in the Appendix.

When the foundation stiffness is not constant, as it may happen in engineering applications, it is necessary to consider a variable elastic foundation to obtain more reliable results. In this research study, two types of variable foundations including linear and parabolic are discussed. The choice of such foundations is based on Zhou [28] and Pradhan et al. [29] to investigate free vibration of beams on variable elastic foundations. An example of variable foundations can be considered as in Table 5, in which Winkler coefficient is a function of $\varepsilon$ and Pasternak coefficient is a function of $\eta$.

The changes in frequency parameter for homogeneous skew plates with variable elastic foundations are pre-
Table 5. Linear and parabolic Winkler-Pasternak foundation coefficients.

\begin{tabular}{ccc}
\hline & Column I: Linear & Column II: Parabolic \\
\hline Winkler & $k_{\mathrm{w}}=k_{01}\left(1-\alpha_{1} \varepsilon\right)$ & $k_{\mathrm{w}}=k_{01}\left(1-\alpha_{2} \varepsilon^{2}\right)$ \\
Pasternak & $k_{\mathrm{p}}=k_{02}\left(1-\alpha_{3} \eta\right)$ & $k_{\mathrm{p}}=k_{02}\left(1-\alpha_{4} \eta^{2}\right)$ \\
\hline
\end{tabular}

sented in Figures 4 and 5 . All $\alpha_{i}$ s of Table 5 have been set to $\alpha$ in this figure, and it varies from 0 to 1.0 with the intervals of 0.2 , and $k_{01}=k_{02}=1000$. The dependency of the frequency to skew angles, and linearly - column I in Table 5 - and parabolically - column II in Table 5 - variable elastic foundations is illustrated in Figures 4 and 5 . 

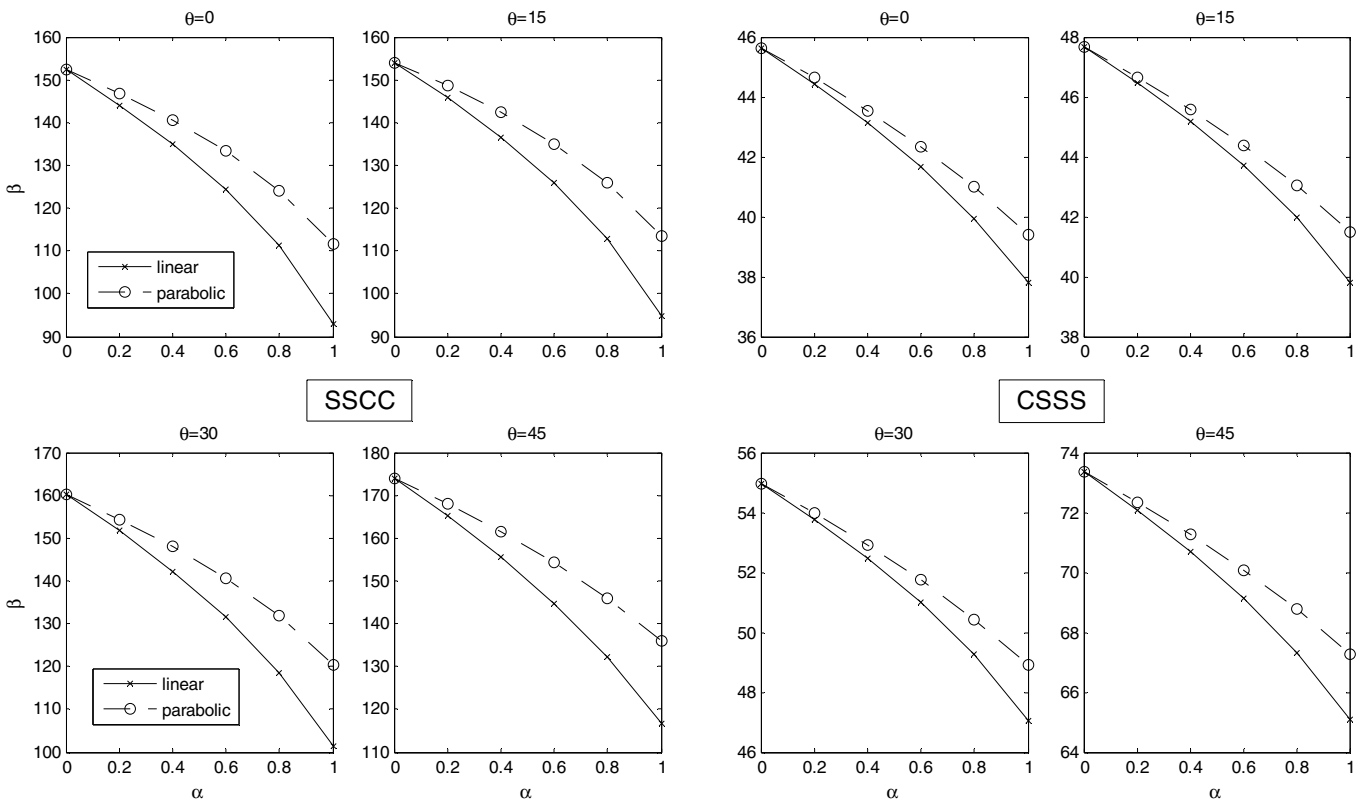

Fig. 4. $\beta$ vs. variable stiffness coefficients of the foundations of homogeneous skew SSCC (left) and CSSS (right) plates.
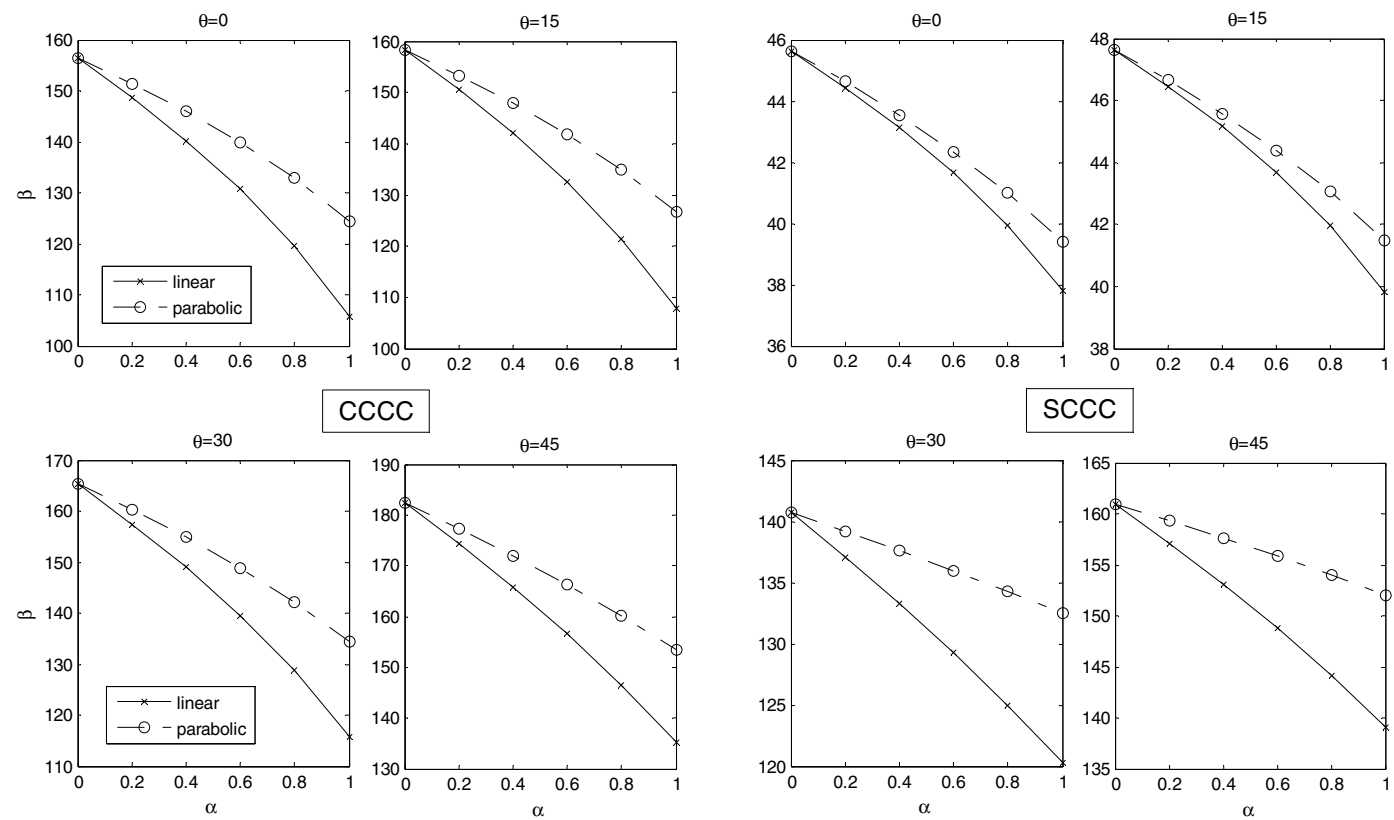

Fig. 5. $\beta$ vs. variable stiffness coefficients of the foundations of homogeneous skew CCCC (left) and SCCC (right) plates.

Table 6. Material properties of the FGM skew plate.

\begin{tabular}{ccccc}
\hline & Material & $E(\mathrm{GPa})$ & $\rho\left(\mathrm{kg} \cdot \mathrm{m}^{-3}\right)$ & $v$ \\
\hline Metal & $S U S 304$ & $201.04 \mathrm{e} 9$ & 8166 & 0.3262 \\
Ceramic & $\mathrm{Si}_{3} \mathrm{~N}_{4}$ & $348.43 \mathrm{e} 9$ & 2377 & 0.2400 \\
\hline
\end{tabular}

\subsection{FGM skew plates on Winkler-Pasternak foundation}

In this section, results for free vibration of FG skew plates on elastic foundation are presented. To do so, material properties are used as in Table 6 .
Natural frequencies of FG skew plates on variable Winkler-Pasternak type elastic foundations are presented in Tables 7, 8 and 9 for CCCC, SSSS and CCSS plates, respectively. These tables include two parts. The first set of columns presents the frequencies when only Winkler foundation has been considered, and Pasternak coefficient has been set to zero. The second set of columns presents the frequencies when Winkler and Pasternak foundations, have been considered. The change in variable coefficients is based in Table 5, in which the Winkler foundation changes along $\varepsilon$, while the Pasternak foundation assumes to be constant. 
Table 7. Frequency parameter for a skew FGM clamped plate on a linearly variable elastic support.

\begin{tabular}{|c|c|c|c|c|c|c|c|c|c|}
\hline \multirow{4}{*}{$\theta$} & \multirow[b]{3}{*}{$n$} & \multicolumn{4}{|c|}{$k_{p}=0$} & \multicolumn{4}{|c|}{$k_{p}=100$} \\
\hline & & \multicolumn{4}{|c|}{$k_{w}=100\left(1-\alpha_{1} \varepsilon\right), \quad \alpha_{1}=0.8$} & \multicolumn{4}{|c|}{$k_{w}=100\left(1-\alpha_{1} \varepsilon\right), \quad \alpha_{1}=0.8$} \\
\hline & & $\infty$ & 10 & 1 & 0 & $\infty$ & 10 & 1 & 0 \\
\hline & mode & & & & & & & & \\
\hline \multirow[t]{5}{*}{0} & 1 & 36.809 & 40.583 & 52.804 & 87.590 & 60.669 & 66.889 & 87.031 & 144.366 \\
\hline & 2 & 73.819 & 81.388 & 105.896 & 175.659 & 105.255 & 116.047 & 150.992 & 250.463 \\
\hline & 3 & 73.820 & 81.388 & 105.896 & 175.660 & 105.256 & 116.047 & 150.992 & 250.464 \\
\hline & 4 & 108.534 & 119.661 & 155.695 & 258.265 & 143.705 & 158.438 & 206.148 & 341.956 \\
\hline & 5 & 132.006 & 145.540 & 189.366 & 314.119 & 168.476 & 185.749 & 241.683 & 400.902 \\
\hline \multirow[t]{5}{*}{15} & 1 & 38.938 & 42.930 & 55.858 & 92.656 & 62.437 & 68.839 & 89.568 & 148.575 \\
\hline & 2 & 73.311 & 80.827 & 105.166 & 174.448 & 103.522 & 114.136 & 148.505 & 246.339 \\
\hline & 3 & 82.995 & 91.503 & 119.058 & 197.492 & 114.281 & 125.998 & 163.939 & 271.941 \\
\hline & 4 & 109.885 & 121.151 & 157.633 & 261.479 & 143.776 & 158.516 & 206.250 & 342.125 \\
\hline & 5 & 139.563 & 153.871 & 200.206 & 332.100 & 175.008 & 192.950 & 251.053 & 416.444 \\
\hline \multirow[t]{5}{*}{30} & 1 & 46.657 & 51.440 & 66.931 & 111.024 & 68.904 & 75.968 & 98.845 & 163.962 \\
\hline & 2 & 81.942 & 90.343 & 117.548 & 194.987 & 109.530 & 120.760 & 157.124 & 260.636 \\
\hline & 3 & 105.587 & 116.412 & 151.467 & 251.251 & 135.037 & 148.881 & 193.713 & 321.330 \\
\hline & 4 & 119.690 & 131.961 & 171.698 & 284.811 & 150.177 & 165.574 & 215.433 & 357.358 \\
\hline & 5 & 167.125 & 184.259 & 239.745 & 397.687 & 199.144 & 219.561 & 285.677 & 473.878 \\
\hline \multirow[t]{5}{*}{45} & 1 & 66.059 & 72.832 & 94.763 & 157.192 & 85.659 & 94.441 & 122.880 & 203.833 \\
\hline & 2 & 106.848 & 117.803 & 153.277 & 254.254 & 130.073 & 143.408 & 186.593 & 309.518 \\
\hline & 3 & 150.469 & 165.896 & 215.852 & 358.053 & 175.108 & 193.060 & 251.196 & 416.682 \\
\hline & 4 & 159.081 & 175.390 & 228.206 & 378.545 & 184.324 & 203.221 & 264.417 & 438.613 \\
\hline & 5 & 208.645 & 230.036 & 299.307 & 496.487 & 233.085 & 256.981 & 334.366 & 554.642 \\
\hline
\end{tabular}

Table 8. Frequency parameter for a skew FGM simply supported plate on a linearly variable elastic support.

\begin{tabular}{|c|c|c|c|c|c|c|c|c|c|}
\hline \multirow{4}{*}{$\theta$} & \multirow[b]{3}{*}{$n$} & \multicolumn{4}{|c|}{$k_{p}=0$} & \multicolumn{4}{|c|}{$k_{p}=100$} \\
\hline & & \multicolumn{4}{|c|}{$k_{w}=100\left(1-\alpha_{1} \varepsilon\right), \quad \alpha_{1}=0.8$} & \multicolumn{4}{|c|}{$k_{w}=100\left(1-\alpha_{1} \varepsilon\right), \quad \alpha_{1}=0.8$} \\
\hline & & $\infty$ & 10 & 1 & 0 & $\infty$ & 10 & 1 & 0 \\
\hline & mode & & & & & & & & \\
\hline \multirow[t]{5}{*}{0} & 1 & 21.202 & 23.376 & 30.415 & 50.452 & 49.229 & 54.276 & 70.621 & 117.145 \\
\hline & 2 & 49.981 & 55.105 & 71.698 & 118.933 & 86.219 & 95.058 & 123.683 & 205.164 \\
\hline & 3 & 49.982 & 55.106 & 71.700 & 118.935 & 86.219 & 95.058 & 123.683 & 205.164 \\
\hline & 4 & 79.378 & 87.516 & 113.870 & 188.887 & 119.155 & 131.371 & 170.931 & 283.539 \\
\hline & 5 & 99.606 & 109.818 & 142.887 & 237.019 & 140.763 & 155.195 & 201.928 & 334.957 \\
\hline \multirow[t]{5}{*}{15} & 1 & 22.232 & 24.511 & 31.892 & 52.902 & 50.101 & 55.237 & 71.871 & 119.218 \\
\hline & 2 & 48.830 & 53.837 & 70.048 & 116.196 & 83.912 & 92.515 & 120.374 & 199.675 \\
\hline & 3 & 56.735 & 62.552 & 81.388 & 135.005 & 92.952 & 102.482 & 133.342 & 221.187 \\
\hline & 4 & 79.590 & 87.749 & 114.173 & 189.390 & 118.216 & 130.336 & 169.584 & 281.303 \\
\hline & 5 & 105.487 & 116.302 & 151.323 & 251.013 & 145.681 & 160.616 & 208.982 & 346.658 \\
\hline \multirow[t]{5}{*}{30} & 1 & 26.141 & 28.821 & 37.500 & 62.205 & 53.291 & 58.755 & 76.448 & 126.810 \\
\hline & 2 & 53.174 & 58.626 & 76.279 & 126.531 & 85.948 & 94.759 & 123.294 & 204.519 \\
\hline & 3 & 72.897 & 80.370 & 104.572 & 173.463 & 107.392 & 118.402 & 154.056 & 255.546 \\
\hline & 4 & 84.942 & 93.651 & 121.852 & 202.126 & 120.400 & 132.744 & 172.717 & 286.501 \\
\hline & 5 & 127.112 & 140.144 & 182.345 & 302.472 & 164.215 & 181.051 & 235.570 & 390.761 \\
\hline \multirow[t]{5}{*}{45} & 1 & 36.722 & 40.487 & 52.679 & 87.383 & 61.709 & 68.036 & 88.524 & 146.842 \\
\hline & 2 & 66.830 & 73.682 & 95.869 & 159.027 & 95.692 & 105.502 & 137.272 & 227.706 \\
\hline & 3 & 104.498 & 115.212 & 149.906 & 248.662 & 134.566 & 148.362 & 193.038 & 320.209 \\
\hline & 4 & 111.785 & 123.246 & 160.358 & 266.001 & 141.872 & 156.417 & 203.518 & 337.594 \\
\hline & 5 & 161.639 & 178.210 & 231.875 & 384.632 & 191.860 & 211.530 & 275.228 & 456.545 \\
\hline
\end{tabular}


Table 9. Frequency parameter for a skew FGM CCSS supported plate on a linearly variable elastic support.

\begin{tabular}{|c|c|c|c|c|c|c|c|c|c|}
\hline \multirow{4}{*}{$\theta$} & \multirow[b]{3}{*}{$n$} & \multicolumn{4}{|c|}{$k_{p}=0$} & \multicolumn{4}{|c|}{$k_{p}=100$} \\
\hline & & \multicolumn{4}{|c|}{$k_{w}=100\left(1-\alpha_{1} \varepsilon\right), \quad \alpha_{1}=0.8$} & \multicolumn{4}{|c|}{$k_{w}=100\left(1-\alpha_{1} \varepsilon\right), \quad \alpha_{1}=0.8$} \\
\hline & & $\infty$ & 10 & 1 & 0 & $\infty$ & 10 & 1 & 0 \\
\hline & mode & & & & & & & & \\
\hline \multirow[t]{5}{*}{0} & 1 & 28.072 & 30.983 & 40.479 & 67.410 & 54.492 & 60.142 & 78.576 & 130.854 \\
\hline & 2 & 61.080 & 67.412 & 88.075 & 146.672 & 95.215 & 105.086 & 137.297 & 228.642 \\
\hline & 3 & 61.330 & 67.688 & 88.436 & 147.274 & 95.279 & 105.157 & 137.389 & 228.796 \\
\hline & 4 & 93.329 & 103.004 & 134.577 & 224.112 & 131.003 & 144.584 & 188.902 & 314.580 \\
\hline & 5 & 115.148 & 127.086 & 166.040 & 276.508 & 154.134 & 170.113 & 222.256 & 370.126 \\
\hline \multirow[t]{5}{*}{15} & 1 & 29.509 & 32.568 & 42.551 & 70.860 & 55.734 & 61.512 & 80.367 & 133.835 \\
\hline & 2 & 60.465 & 66.733 & 87.188 & 145.195 & 93.208 & 102.871 & 134.403 & 223.822 \\
\hline & 3 & 68.873 & 76.013 & 99.312 & 165.386 & 102.982 & 113.658 & 148.496 & 247.292 \\
\hline & 4 & 94.107 & 103.863 & 135.699 & 225.981 & 130.523 & 144.054 & 188.209 & 313.427 \\
\hline & 5 & 121.467 & 134.060 & 175.151 & 291.681 & 159.519 & 176.057 & 230.021 & 383.057 \\
\hline \multirow[t]{5}{*}{30} & 1 & 34.890 & 38.507 & 50.310 & 83.782 & 60.263 & 66.510 & 86.897 & 144.710 \\
\hline & 2 & 66.829 & 73.757 & 96.365 & 160.478 & 97.060 & 107.122 & 139.957 & 233.071 \\
\hline & 3 & 87.641 & 96.727 & 126.375 & 210.454 & 120.104 & 132.555 & 173.186 & 288.408 \\
\hline & 4 & 101.293 & 111.794 & 146.061 & 243.237 & 134.457 & 148.396 & 193.882 & 322.874 \\
\hline & 5 & 143.918 & 158.839 & 207.526 & 345.594 & 179.060 & 197.623 & 258.198 & 429.980 \\
\hline \multirow[t]{5}{*}{45} & 1 & 48.532 & 53.563 & 69.981 & 116.541 & 71.822 & 79.268 & 103.565 & 172.467 \\
\hline & 2 & 85.720 & 94.606 & 123.605 & 205.841 & 111.750 & 123.335 & 161.140 & 268.348 \\
\hline & 3 & 123.828 & 136.665 & 178.556 & 297.350 & 151.783 & 167.518 & 218.865 & 364.478 \\
\hline & 4 & 131.311 & 144.924 & 189.346 & 315.320 & 159.798 & 176.364 & 230.423 & 383.725 \\
\hline & 5 & 168.893 & 186.402 & 243.538 & 405.566 & 198.063 & 218.596 & 285.600 & 475.612 \\
\hline
\end{tabular}

It was previously mentioned that a pure ceramic plate is achieved for $n=0$, and a pure metal plate is achieved for $n=\infty$. It is obtained from Tables 7-9 that the frequency increases if one chooses lower values of $n$, e.g. moving from metal to ceramic. Moreover, as discussed before, the plate frequency is directly dependent to skew angle and Winkler-Pasternak coefficients for different boundary conditions.

\section{Conclusion remarks}

In this research study, Rayleigh-Ritz formulation was employed to obtain approximate but highly accurate solution for free vibration of skew homogeneous and FGM plates resting on variable elastic foundations. The formulation for the energy of the variable Winkler and Pasternak foundations together with the skew plate was derived. A number of comparisons were made with those available results in the literature and showed an excellent agreement particularly in lower mode frequencies. Finally, the dependency of the free vibration of skew plates on FG properties, skew angles, boundary conditions, foundation stiffness parameters, and linearly or parabolically variable Winkler-Pasternak elastic foundations were investigated. All results presented in this paper may serve to validate other analytical and numerical methods. In future research, it would be beneficial to study the free vibration analysis of piezoelectric skew plates resting on elastic foundations

\section{Appendix}

More results for the interaction of structurefoundation of homogeneous plates are presented in the following tables. 
M.J. Ketabdari et al.: Mechanics \& Industry 17, 107 (2016)

Table A.1. Frequency parameter of a homogeneous skew CCSS plate on Winkler-Pasternak foundation.

\begin{tabular}{cccccccc}
\hline \multicolumn{2}{c}{$\left(\bar{k}_{\mathrm{w}}, \bar{k}_{\mathrm{p}}\right)$} & $(0,100)$ & $(0,1000)$ & $(100,0)$ & $(100,100)$ & $(10,10)$ & $(100,1000)$ \\
\hline$\theta$ & Mode & & & & & & \\
\hline 0 & 1 & 53.968 & 147.290 & 28.858 & 54.887 & 31.078 & 147.629 \\
& 2 & 94.913 & 236.326 & 61.433 & 95.439 & 64.979 & 236.537 \\
& 3 & 94.975 & 236.328 & 61.673 & 95.500 & 65.178 & 236.540 \\
& 4 & 130.781 & 303.203 & 93.554 & 131.163 & 97.527 & 303.368 \\
& 5 & 153.945 & 342.299 & 115.330 & 154.270 & 119.428 & 342.445 \\
\hline 15 & 1 & 55.240 & 149.200 & 30.234 & 56.108 & 32.494 & 149.524 \\
& 2 & 92.909 & 229.956 & 60.802 & 93.427 & 64.157 & 230.166 \\
& 3 & 102.712 & 249.087 & 69.176 & 103.181 & 72.727 & 249.281 \\
& 4 & 130.307 & 299.042 & 94.321 & 130.677 & 98.136 & 299.204 \\
\hline \multirow{4}{*}{0} & 5 & 159.343 & 347.267 & 121.634 & 159.646 & 125.616 & 347.406 \\
& 1 & 59.856 & 155.707 & 35.445 & 60.576 & 37.749 & 155.985 \\
& 2 & 96.803 & 229.941 & 67.106 & 97.250 & 70.166 & 230.129 \\
& 3 & 119.898 & 271.351 & 87.855 & 120.258 & 91.210 & 271.510 \\
& 4 & 134.270 & 295.305 & 101.472 & 134.592 & 104.895 & 295.452 \\
& 5 & 178.922 & 364.796 & 144.046 & 179.164 & 147.675 & 364.915 \\
\hline 45 & 1 & 71.547 & 170.280 & 48.861 & 72.040 & 51.078 & 170.488 \\
& 2 & 111.570 & 240.002 & 85.898 & 111.886 & 88.492 & 240.149 \\
& 3 & 151.648 & 301.943 & 123.949 & 151.881 & 126.775 & 302.060 \\
& 4 & 159.672 & 313.780 & 131.428 & 159.893 & 134.323 & 313.893 \\
& 5 & 197.959 & 366.779 & 168.980 & 198.138 & 171.937 & 366.875 \\
\hline
\end{tabular}

Table A.2. Frequency parameter of a homogeneous skew CSSS plate on Winkler-Pasternak foundation.

\begin{tabular}{cccccccc}
\hline \multicolumn{2}{c}{$\left(\bar{k}_{\mathrm{w}}, \bar{k}_{\mathrm{p}}\right)$} & $(0,100)$ & $(0,1000)$ & $(100,0)$ & $(100,100)$ & $(10,10)$ & $(100,1000)$ \\
\hline$\theta$ & Mode & & & & & & \\
\hline 0 & 1 & 30.215 & 42.414 & 24.336 & 30.289 & 25.188 & 42.422 \\
& 2 & 56.850 & 66.442 & 52.004 & 56.889 & 52.769 & 66.447 \\
& 3 & 81.945 & 97.915 & 66.403 & 82.042 & 70.858 & 97.925 \\
& 4 & 105.529 & 113.077 & 91.895 & 105.549 & 99.801 & 113.080 \\
& 5 & 106.923 & 120.545 & 101.250 & 106.949 & 101.935 & 120.552 \\
\hline 15 & 1 & 31.989 & 44.478 & 25.828 & 32.057 & 26.968 & 44.487 \\
& 2 & 59.725 & 69.093 & 54.160 & 59.755 & 55.658 & 69.097 \\
& 3 & 87.113 & 103.950 & 70.353 & 87.230 & 75.036 & 103.959 \\
& 4 & 103.766 & 112.605 & 90.990 & 103.794 & 97.619 & 112.608 \\
& 5 & 118.876 & 133.925 & 109.874 & 118.933 & 111.870 & 133.932 \\
\hline 0 & 1 & 38.545 & 51.952 & 31.119 & 38.597 & 33.297 & 51.959 \\
& 2 & 70.203 & 79.109 & 61.206 & 70.223 & 64.957 & 79.112 \\
& 3 & 105.398 & 123.438 & 85.454 & 105.563 & 90.782 & 123.443 \\
& 4 & 111.870 & 125.503 & 95.665 & 111.931 & 102.914 & 125.514 \\
& 5 & 146.137 & 169.220 & 133.265 & 146.242 & 136.315 & 169.231 \\
\hline 45 & 1 & 55.466 & 70.622 & 44.202 & 55.498 & 48.508 & 70.629 \\
& 2 & 95.530 & 105.757 & 77.582 & 95.570 & 84.612 & 105.759 \\
& 3 & 135.673 & 158.850 & 114.616 & 135.785 & 121.552 & 158.861 \\
& 4 & 150.686 & 178.146 & 125.599 & 150.860 & 133.383 & 178.161 \\
& 5 & 184.465 & 240.065 & 158.207 & 184.586 & 164.008 & 240.088 \\
\hline
\end{tabular}


M.J. Ketabdari et al.: Mechanics \& Industry 17, 107 (2016)

Table A.3. Frequency parameter of a homogeneous skew SCCC plate on Winkler-Pasternak foundation.

\begin{tabular}{cccccccc}
\hline \multicolumn{2}{c}{$\left(\bar{k}_{\mathrm{w}}, \bar{k}_{\mathrm{p}}\right)$} & $(0,100)$ & $(0,1000)$ & $(100,0)$ & $(100,100)$ & $(10,10)$ & $(100,1000)$ \\
\hline$\theta$ & Mode & & & & & & \\
\hline 0 & 1 & 52.509 & 125.538 & 33.306 & 52.996 & 35.442 & 125.728 \\
& 2 & 92.170 & 185.294 & 66.409 & 92.405 & 72.366 & 185.401 \\
& 3 & 111.183 & 259.795 & 72.006 & 111.632 & 74.469 & 259.866 \\
& 4 & 146.976 & 280.951 & 103.182 & 147.271 & 109.343 & 281.117 \\
& 5 & 151.615 & 337.912 & 122.101 & 151.751 & 133.850 & 338.037 \\
\hline 15 & 1 & 54.628 & 127.947 & 35.174 & 55.081 & 37.570 & 128.128 \\
& 2 & 95.850 & 188.793 & 67.601 & 96.073 & 73.074 & 188.895 \\
& 3 & 115.264 & 265.663 & 78.700 & 115.687 & 82.107 & 265.732 \\
& 4 & 146.439 & 285.319 & 104.236 & 146.699 & 110.848 & 285.478 \\
& 5 & 163.208 & 340.253 & 130.548 & 163.367 & 141.173 & 340.376 \\
\hline 0 & 1 & 62.288 & 136.461 & 41.931 & 62.645 & 45.171 & 136.614 \\
& 2 & 107.917 & 201.527 & 75.270 & 108.124 & 81.396 & 201.617 \\
& 3 & 131.386 & 285.662 & 99.393 & 131.720 & 103.656 & 285.729 \\
& 4 & 154.029 & 300.577 & 112.638 & 154.275 & 120.039 & 300.715 \\
& 5 & 194.433 & 351.254 & 156.070 & 194.559 & 166.001 & 351.365 \\
\hline 45 & 1 & 81.375 & 157.180 & 59.017 & 81.600 & 63.743 & 157.290 \\
& 2 & 133.035 & 233.422 & 96.981 & 133.220 & 104.167 & 233.492 \\
& 3 & 176.266 & 323.111 & 138.507 & 176.511 & 146.281 & 323.191 \\
& 4 & 179.832 & 337.494 & 148.603 & 179.984 & 155.221 & 337.593 \\
& 5 & 232.753 & 394.920 & 186.267 & 232.900 & 197.241 & 394.988 \\
\hline
\end{tabular}

\section{References}

[1] M. Koizumi, FGM activities in Japan, Compos. Part B Eng. 8368 (1997) 1-4

[2] R.K. Kaul, V. Cadambe, The natural frequencies of thin skew plates, Aeronaut. Q. 7 (1956) 337-352

[3] C.M. Wang, K.K. Ang, L. Yang, E. Watanabe, Free Vibration of Skew Sandwich Plates With Laminated Facings, J. Sound Vib. 235 (2000) 317-340

[4] K.S. Woo, C.H. Hong, P.K. Basu, C.G. Seo, Free vibration of skew Mindlin plates by p-version of FEM, J. Sound Vib. 268 (2003) 637-656

[5] X. Zhao, Y.Y. Lee, K.M.Ã. Liew, Free vibration analysis of functionally graded plates using the element-free $\mathrm{kp}$-Ritz method, J. Sound Vib. 319 (2009) 918-939

[6] Ö. Civalek, Nonlinear analysis of thin rectangular plates on Winkler-Pasternak elastic foundations by DSC-HDQ methods, Appl. Math. Model. 31 (2007) 606-624

[7] H. Akhavan, S. Hosseini Hashemi, H.R. Damavandi Taher, a. Alibeigloo, S. Vahabi, Exact solutions for rectangular Mindlin plates under in-plane loads resting on Pasternak elastic foundation. Part I: Buckling analysis. Comput. Mater. Sci. 44 (2009) 968-978

[8] H.A. Atmane, A. Tounsi, I. Mechab, E.A.A. Bedia, Free vibration analysis of functionally graded plates resting on Winkler-Pasternak elastic foundations using a new shear deformation theory, Int. J. Mech. Mater. Des. 6 (2010) 113121

[9] A. Joodaky, I. Joodaky, M. Hedayati, R. Masoomi, E. Borzabadi, Deflection and stress analysis of thin FGM skew plates on Winkler foundation with various boundary conditions using extended Kantorovich method, Compos. Part B. 51 (2013) 191-196
[10] A. Fekrar, M.S.A. Houari, A. Tounsi, S.R. Mahmoud, A new five-unknown refined theory based on neutral surface position for bending analysis of exponential graded plates, Meccanica 49 (2014) 795-810

[11] Y. Benveniste, A new approach to the application of Mori-Tanaka's theory in composite materials, Mech. Mater. 6 (1987) 147-157

[12] Z. Belabed, M.S. Ahmed Houari, A. Tounsi, S.R. Mahmoud, O. Anwar Bég, An efficient and simple higher order shear and normal deformation theory for functionally graded material (FGM) plates, Compos. Part B Eng. 60 (2014) 274-283

[13] S.A. Yahia, H.A. Atmane, M.S.A. Houari, A. Tounsi, Wave propagation in functionally graded plates with porosities using various higher-order shear deformation plate theories, Struct. Eng. Mech. 53 (2015) 1143-1165

[14] A.A. Bousahla, M.S.A. Houari, A. Tounsi, E.A. Adda Bedia, a Novel Higher Order Shear and Normal Deformation Theory Based on Neutral Surface Position for Bending Analysis of Advanced Composite Plates, Int. J. Comput. Methods. 11 (2014) 1350082

[15] L.O. Larbi, A. Kaci, M.S.A. Houari, A. Tounsi, An Efficient Shear Deformation Beam Theory Based on Neutral Surface Position for Bending and Free Vibration of Functionally Graded Beams \#, Mech. Based Des. Struct. Mach. 41 (2013) 421-433

[16] S.A . Eftekhari, A.A. Jafari, Modified mixed Ritz-DQ formulation for free vibration of thick rectangular and skew plates with general boundary conditions, Appl. Math. Model. 37 (2013) 7398-7426

[17] R.B. Bhat, Natural frequencies of rectangular plates using characteristic orthogonal polynomials in Rayleigh-Ritz method, J. Sound Vib. 102 (1985) 493-499 
[18] O. Beslin, J. Nicolas, A hierarchical functions set for predicting very high order plate bending modes with any boundary conditions, J. Sound Vib. 202 (1997) 633-655

[19] J. Yang, H. Shen, Dynamic response of initially stressed functionally graded rectangular thin plates, Compos. Struct. 54 (2001) 497-508

[20] X. Wang, Y. Wang, Z. Yuan, Accurate vibration analysis of skew plates by the new version of the differential quadrature method, Appl. Math. Model. 38 (2014) 926-937

[21] A.W. Leissa, Vibration of Plates, NASA SP-160 (1969)

[22] B. Singh, S. Chakraverty, Flexural vibration of skew plates using boundary characteristic orthogonal polynomials in two variables, J. Sound Vib. 173 (1994) 157-178

[23] M.A.A. Meziane, H.H. Abdelaziz, A. Tounsi, An efficient and simple refined theory for buckling and free vibration of exponentially graded sandwich plates under various boundary conditions, J. Sandw. Struct. Mater. 16 (2014) 293-318

[24] K. Nedri, N. El Meiche, A. Tounsi, Free vibration analysis of laminated composite plates resting on elastic foundations by using a refined hyperbolic shear deformation theory, Mech. Compos. Mater. 49 (2014) 629-640
[25] B. Bouderba, M.S.A. Houari, A. Tounsi, Thermomechanical bending response of FGM thick plates resting on Winkler-Pasternak elastic foundations, Steel Compos. Struct. 14 (2013) 85-104

[26] S. Motaghian, M. Mofid, J.E. Akin, On the free vibration response of rectangular plates, partially supported on elastic foundation, Appl. Math. Model. 36 (2012) 4473-4482

[27] S.A. Sheikholeslami, A.R. Saidi, Vibration analysis of functionally graded rectangular plates resting on elastic foundation using higher-order shear and normal deformable plate theory, Compos. Struct. 106 (2013) 350-361

[28] D. Zhou, A general solution to vibrations of beams on variable Winkler elastic foundation, Comput. Struct. 47 (1993) 83-90

[29] S.C.Ã. Pradhan, T. Murmu, Thermo-mechanical vibration of FGM sandwich beam under variable elastic foundations using differential quadrature method, J. Sound Vib. 321 (2009) 342-362 